\title{
Ultrasound as a Tool to Study Muscle-Tendon Functions during Locomotion: A Systematic Review of Applications
}

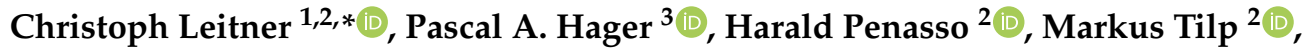 \\ Luca Benini ${ }^{3,4, *,+}+\mathbb{D}_{\text {, Christian Peham }}{ }^{5, *},+$ and Christian Baumgartner ${ }^{1,+}+\mathbb{D}$ \\ 1 Institute of Health Care Engineering with European Testing Center of Medical Devices, Graz University of \\ Technology, Stremayrgasse 16/II, 8010 Graz, Austria; christian.baumgartner@tugraz.at \\ 2 Institute of Sport Science, University of Graz, Mozartgasse 14, 8010 Graz, Austria; \\ harald.penasso@gmail.com (H.P.); markus.tilp@uni-graz.at (M.T.) \\ 3 Integrated Systems Laboratory, ETH Zürich, Gloriastrasse 35, 8092 Zürich, Switzerland; \\ phager@iis.ee.ethz.ch \\ 4 Electrical, Electronic and Information Engineering - DEI, Università di Bologna, Viale del Risorgimento 2, \\ 40136 Bologna, Italy \\ 5 Department for Companion Animals and Horses, University of Veterinary Medicine Vienna, Veterinärplatz 1, \\ 1210 Wien, Austria \\ * Correspondence: christoph.leitner@uni-graz.at (C.L.); lbenini@iis.ee.ethz.ch (L.B.); \\ christian.peham@vetmeduni.ac.at (C.P.); Tel.: +43-(0)664-156-3900 (C.L.); +41-(0)44-632-66-64 (L.B.); \\ +43-(0)1-25077-5517 (C.P.) \\ + These authors contributed equally to this work.
}

Received: 31 July 2019; Accepted: 2 October 2019; Published: 5 October 2019

\begin{abstract}
Movement science investigating muscle and tendon functions during locomotion utilizes commercial ultrasound imagers built for medical applications. These limit biomechanics research due to their form factor, range of view, and spatio-temporal resolution. This review systematically investigates the technical aspects of applying ultrasound as a research tool to investigate human and animal locomotion. It provides an overview on the ultrasound systems used and of their operating parameters. We present measured fascicle velocities and discuss the results with respect to operating frame rates during recording. Furthermore, we derive why muscle and tendon functions should be recorded with a frame rate of at least $150 \mathrm{~Hz}$ and a range of view of $250 \mathrm{~mm}$. Moreover, we analyze why and how the development of better ultrasound observation devices at the hierarchical level of muscles and tendons can support biomechanics research. Additionally, we present recent technological advances and their possible application. We provide a list of recommendations for the development of a more advanced ultrasound sensor system class targeting biomechanical applications. Looking to the future, mobile, ultrafast ultrasound hardware technologies create immense opportunities to expand the existing knowledge of human and animal movement.
\end{abstract}

Keywords: ultrasound; system design; form factor; range of view; frame rate; in vivo; biomonitoring; human and animal locomotion; muscle; tendon; fascicle; velocity

\section{Introduction}

Species living on Earth are exposed to gravity. As a result of the cyclic nature of locomotion and due to gravitational force, muscle-tendon structures (Figure 1) repeatedly function in eccentric (elongation) and concentric (shortening) ways, producing force in both conditions. The combination of eccentric and concentric actions in tissues forms a natural type of muscle and tendon function known as the stretch-shortening cycle (SSC) [1]. Studies from the 1980s and early 1990s conceived the SSC as a muscle function during human walking and running [1,2], without being able to actually observe the 
structure during movement. Newer studies performed with ultrasound (US) were able to capture the distinct contributions of muscles and tendons within the muscle-tendon unit (MTU), respectively.

The MTU is not one uniform unit with consistent properties, but a mixture of active/passive and contractile/visco-elastic elements with different properties and roles during the SSC. Besides force generation in muscles, elastic energy storage and return is a basic principle in human and animal locomotion [3-5]. Studies have shown that the MTU can elongate even if the muscle is isometrically or concentrically contracted [6-9]. Contractile elements of particular MTUs used for locomotion in horses [10] and to a greater extent in camels [11] are reduced to a rudiment. This leaves the remaining tendon structures running virtually uninterrupted from origin to insertion. Hence, the lengthening and shortening of muscle fascicles contribute little to the total length change of the MTU. In conclusion, the interaction of the whole MTU is responsible for the resultant movement.

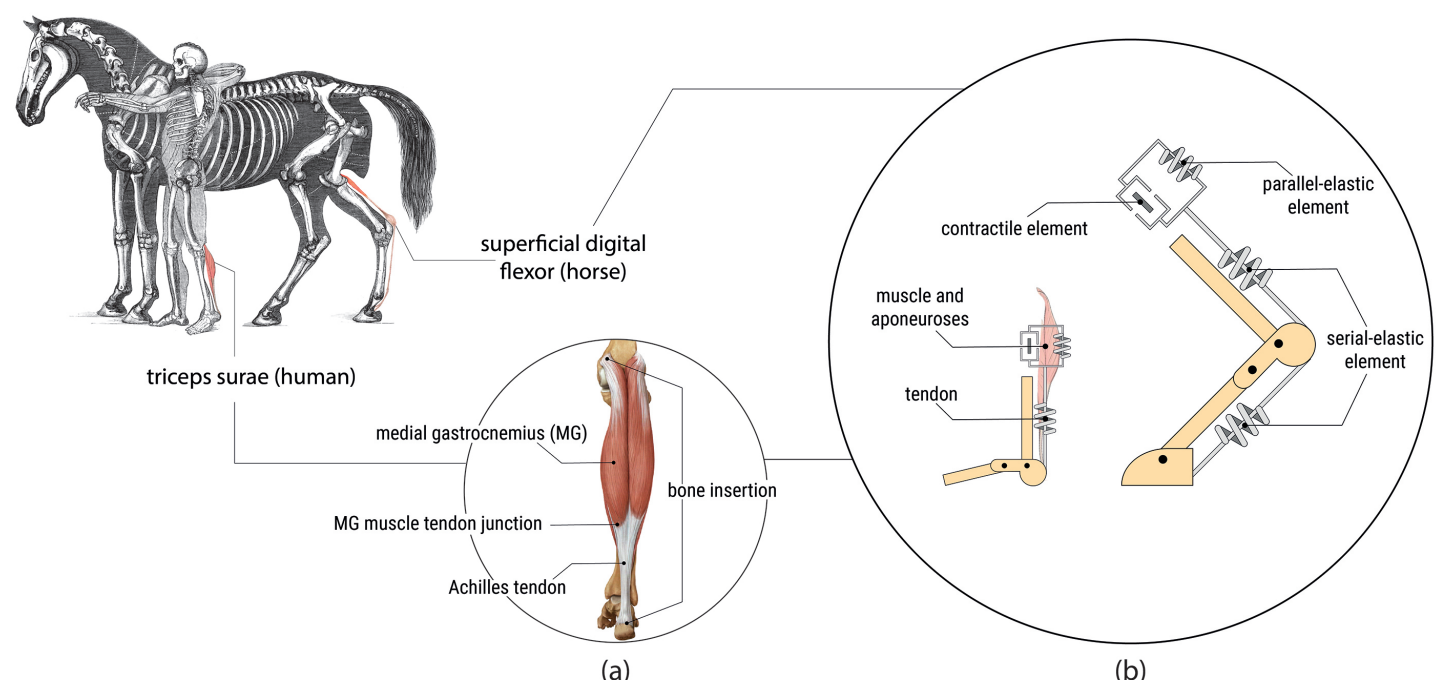

(a)

(b)

Figure 1. Components and modelling of Hill-type muscle-tendon units (MTUs) in humans and horses: (a) shows the human plantarflexor triceps surae (TS) and the components and landmarks of the medial gastrocnemius (MG) MTU; (b) shows a simple modeling approach [12] of the human MG MTU and the equine superficial digital flexor (SFDF) MTU [11]. An alignment of elastic springs and contractile elements is used to model the functions of muscles (active) and tendons (passive).

Ultrasound found its way into movement science laboratories in the 1990s. As a research tool US has advantages over other tissue imaging techniques. Most significantly, US is a direct, non-invasive, in-vivo method in which test subjects are not exposed to radiation. Hence, even long-duration tests can be repeated frequently [13]. The use of US imagers allows the direct and real-time examination of tissues and their response to mechanical stress and muscle contraction by looking inside the body [14]. During movement, tendons and aponeuroses transmit forces from contracting muscles to the bone and act as biological springs, storing and releasing elastic energy [5,15]. As such, US provides a valuable tool for understanding how muscles and tendons interact or might get injured due to acute or chronic loading [14].

Recently, 2d B-Mode US has also been applied to investigate (biomonitor) muscle and tendon dynamics in complex movement tasks in humans (e.g., walking, running, and jumping). Currently, movement science utilizes clinical US devices for research purposes. US imagers built for medical applications are not entirely adequate for direct in-vivo measurements of muscle and tendon dynamics, 
as stated in previous reviews [14-17]. They limit biomechanical research mainly by their form factor, range of view, and spatio-temporal resolution. This restricts the ability to biomonitor the whole muscle-tendon complex and its non-linear behavior. Advances in human and animal locomotion research depend on the development of new and better observation devices and sensors at any hierarchical level of the body [16].

This article investigates US-based biomonitoring (2d B-Mode) of muscle and tendon dynamics during locomotion. We review the state-of-the-art and shortcomings of the current technology. Furthermore, we take a closer look at the system designs and form factors of US platforms and derive why muscle and tendon functions should be recorded with frame rates of at least $150 \mathrm{~Hz}$ and a range of view of $250 \mathrm{~mm}$. Moreover, we provide a list of suggestions for future developments of a US system class targeting biomechanics research.

The Materials and Methods of the systematic investigation are presented in Section 2 with supplementary material in Appendix A. Section 3 outlines which US platforms and parameters are currently used for investigating muscle and tendon structures during locomotion. Furthermore, we provide an overview of measured fascicle velocities in lower limbs and present the results in the context of operating frame rates during recording. Section 4 discusses these results and proposes future engineering directions for US systems in movement science research.

\section{Materials and Methods}

A systematic approach based on the PRISMA guidelines was used [18]. The database search including SCOPUS, MEDLINE (PubMed), and Google Scholar led to the inclusion of 17 studies (Figure A1). All identified studies (Table 1) investigated muscle and tendon complexes in healthy humans using US during locomotion speeds higher than $1.9 \mathrm{~ms}^{-1}$. Applying the same inclusion and exclusion criteria, no animal studies could be identified. The protocol including a flow diagram of the search strategy, screening, evaluation, as well as the inclusion and exclusion criteria can be found in Appendix A.

Experimental data was extracted manually and digitally (FIGURE DIGITALIZER V1.0, Hongxue Cai, Mathworks, MA, USA) by independent surveyors. Not all of the studies provided sufficient information (e.g., only statistical values) to extract all parameters for the investigated time intervals.

We introduced a set of quantities to specify the spatio-temporal resolution. The mean tissue velocity $\left(\mathrm{v}_{\text {tisMean }}\right)$ was calculated by dividing the tissue displacement $\left(\Delta \mathrm{L}_{\mathrm{tis}}\right)$ by the time interval $(\Delta \mathrm{t})$ in which this displacement occurred during the gait cycle (Equation (1)):

$$
\mathrm{v}_{\text {tisMean }}=\frac{\Delta \mathrm{L}_{\mathrm{tis}}}{\Delta \mathrm{t}}\left[\mathrm{ms}^{-1}\right] .
$$

Equation (2) describes the spatio-temporal resolution of the US sensor system, recording frames at a chosen frame rate (fps). The covered distance (spatio-temporal resolution) per frame ( $\left.\mathrm{dpf}_{\mathrm{t}}\right)$ was calculated by dividing the mean tissue velocity $\left(\mathrm{v}_{\text {tisMean }}\right)$ by the selected frame rate:

$$
\mathrm{dpf}_{\mathrm{t}}=\frac{\mathrm{v}_{\text {tisMean }}}{\mathrm{fps}}[\mathrm{m}] \text {. }
$$

The number of recorded frames during the time interval is given as:

$$
\mathrm{fpt}=\frac{\Delta \mathrm{L}_{\mathrm{tis}}}{\mathrm{dpf}_{\mathrm{t}}}[-]
$$




\section{Results}

\subsection{System Designs and Form Factors}

The utilized US systems and their settings are presented in Table 1. Two different US platforms (Echo Blaster by Telemed and ProSound by Hitachi-Aloka) are mainly used for studying muscle and tendon functions during movement. Both systems can be classified as "commercial systems for research purposes" [19], since they have add-on research interfaces. These add I/O functionality for researchers to enable synchronization of US data between different devices (e.g., force plates, $3 \mathrm{~d}$ motion capture systems, etc.; Figure 3) and authorize access to radio frequency (RF) data for back-end processing.

Except for Suzuki et al. [20], research groups used single-transducer arrangements to record muscle and tendon functions. They predominantly applied linear array transducers with a size of 40-60 mm and 96-128 imaging channels. The reviewed studies indicate that flat veterinary transducer probe shapes (Figure 2) have advantages over classical linear array transducer shapes [21,22].

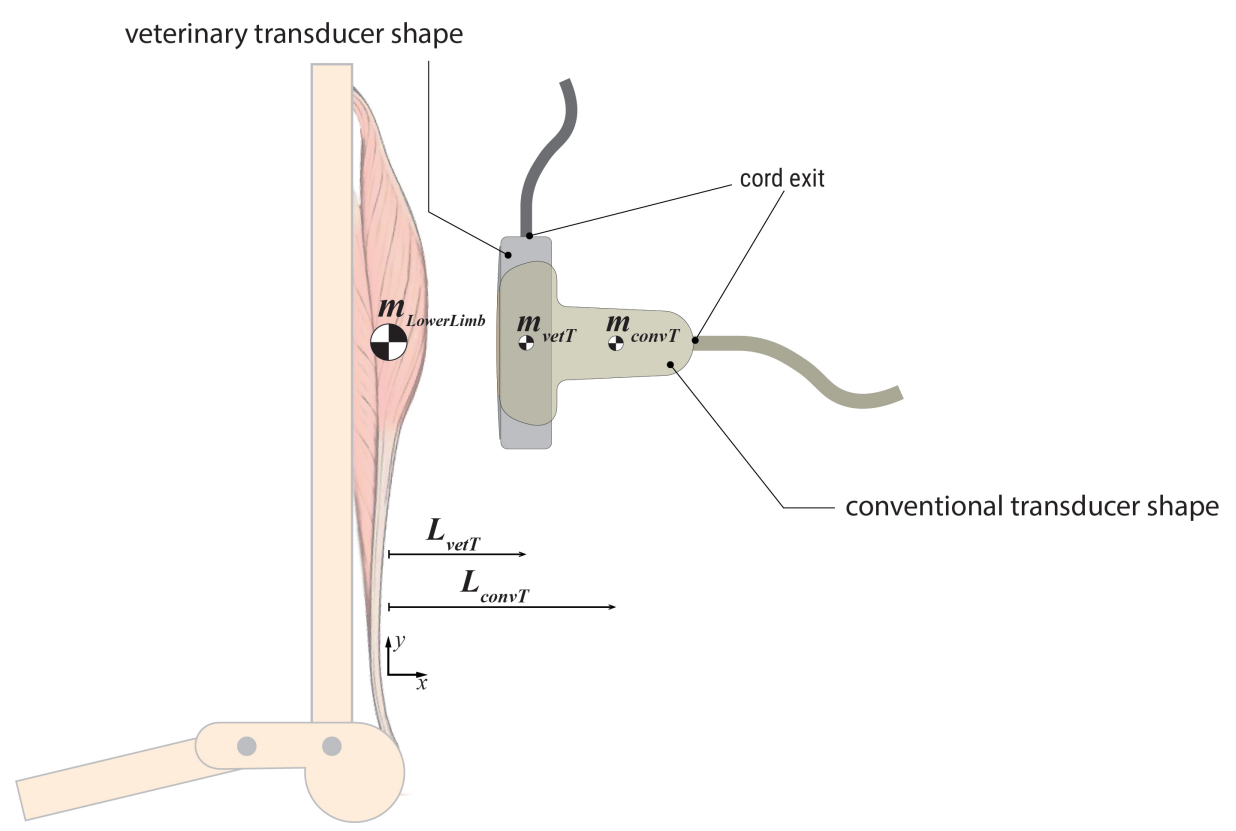

Figure 2. Transducer form factors and their influence on image quality: To build less-interfering setups and reduce imaging bias caused by momentum on the probe head, the lever arm between the centers-of-mass $(\mathrm{CM})$ of moving body parts $\left(m_{\text {LowerLimb }}\right)$ and ultrasound transducer probes $\left(m_{\mathrm{vetT}}-\mathrm{CM}\right.$ veterinary transducer, $m_{\text {convT }}-\mathrm{CM}$ conventional transducer) should be as small as possible. Veterinary transducers have shorter lever arms $\left(L_{\mathrm{vetT}}\right)$ than conventional probes $\left(L_{\text {convT }}\right)$.

As presented in Table 1, most mounting devices are hand-tailored to fit the anatomical form. Elastic straps or compressive self-adhesive bandages are used for probe fixation during motion. For example, Ishikawa et al. [23] specified the weight of $130 \mathrm{~g}$ for their probe fixation, including the probe head.

\subsection{Recording Muscle and Tendon Tissue Dynamics}

We present mean measured fascicle velocities and calculated frame-rate-dependent parameters for full stance and stride phases in Table 2, and for critical time intervals during the gait cycle-where maximum tissue velocities occur-in Table 3. 
Table 1. US sensor system and transducer specifications as well as operating parameters in the biomonitoring of muscle and tendon dynamics during locomotion.

\begin{tabular}{|c|c|c|c|c|c|c|}
\hline Study & US System & US Transducer & Arrangement & Mounting & Center Frequency (MHz) & Frame Rate $(\mathrm{Hz})$ \\
\hline Suzuki 2019 [20] & $\begin{array}{c}\text { ProSound } \alpha 7 \\
\text { Hitachi-Aloka (Tokyo, JP) }\end{array}$ & $\begin{array}{l}60 \mathrm{~mm} \text {, linear array (UST-5712) } \\
50 \mathrm{~mm} \text {, linear array (UST-567) }\end{array}$ & double & $\begin{array}{l}\text { scratch-build fixture, } \\
\text { transmission gel, bandage }\end{array}$ & 7.5 & 110 \\
\hline Lai 2018 [24] & $\begin{array}{l}\text { Echo Blaster } 128 \\
\text { Telemed (Vilnius, LT) }\end{array}$ & $\begin{array}{l}60 \text { mm, linear array, } \\
96 \text { channels }\end{array}$ & single & - & 7 & 80 \\
\hline Bohm 2018 [7] & $\begin{array}{c}\text { MyLab60 } \\
\text { Esaote (Genova, IT) }\end{array}$ & $\begin{array}{c}100 \mathrm{~mm} \text {, linear array (LA923) } \\
192 \text { channels }\end{array}$ & single & $\begin{array}{l}\text { neoprene plastic cast, } \\
\text { elastic straps }\end{array}$ & 10 & 43 \\
\hline Swinnen 2018 [25] & $\begin{array}{l}\text { Echo Blaster } 128 \text { CEXT } \\
\text { Telemed (Vilnius, LT) }\end{array}$ & $\begin{array}{l}60 \mathrm{~mm} \text {, linear array } \\
(L V 7.5 / 60 / 128 \mathrm{Z}-2)\end{array}$ & single & tape, elastic bandage & 8 & 86 \\
\hline Maharaj 2016 [26] & $\begin{array}{l}\text { Echo Blaster } 128 \mathrm{UAB} \\
\text { Telemed (Vilnius, LT) }\end{array}$ & $\begin{array}{l}96 \text { channels } \\
(\text { LV7.5/60/96) }\end{array}$ & single & plastic mould, bandage & 6 & 80 \\
\hline Cronin 2016 [27] & $\begin{array}{c}\text { Acuson P300 } \\
\text { Siemens (Erlangen, DE) }\end{array}$ & $50 \mathrm{~mm}$ & single & elastic bandage & 7.5 & 42 \\
\hline Sano 2015a [28] & $\begin{array}{l}\text { ProSound: C3cv / } \alpha 10 \\
\text { Hitachi-Aloka (Tokyo, JP) }\end{array}$ & $\begin{array}{c}40 \mathrm{~mm} / 60 \mathrm{~mm} \text {, linear array } \\
20-30 \mathrm{~g}\end{array}$ & single & custom-made Styrofoam cast & 13 & $58 / 65$ \\
\hline Lai 2015 [29] & $\begin{array}{c}\text { Echo Blaster } 128 \\
\text { Telemed (Vilnius, LT) }\end{array}$ & $\begin{array}{l}60 \mathrm{~mm} \text {, linear array, } \\
96 \text { channels }\end{array}$ & single & self-adhesive bandage & 7 & 80 \\
\hline Sano $2015 b$ [30] & $\begin{array}{c}\text { ProSound } \alpha 10 \\
\text { Hitachi-Aloka (Tokyo, JP) }\end{array}$ & $\begin{array}{l}60 \mathrm{~mm} \text {, linear array } \\
\text { custom-made, } 180 \mathrm{~g}\end{array}$ & single & custom-made support device & 13 & 117 \\
\hline
\end{tabular}


Table 1. Cont.

\begin{tabular}{|c|c|c|c|c|c|c|}
\hline Study & US System & US Transducer & Arrangement & Mounting & Center Frequency (MHz) & Frame Rate (Hz) \\
\hline Cronin 2013 [31] & $\begin{array}{l}\text { Echo Blaster } 128 \\
\text { Telemed (Vilnius, LT) }\end{array}$ & $\begin{array}{l}60 \mathrm{~mm} \text {, linear array } \\
96 \text { channels }\end{array}$ & single & $\begin{array}{l}\text { US-system in backpack ( } 5 \mathrm{~kg}) \text {, } \\
\text { compressive bandage }\end{array}$ & 7 & 80 \\
\hline Farris 2012 [32] & $\begin{array}{c}- \\
\text { Telemed (Vilnius, LT) }\end{array}$ & $\begin{array}{l}\text { linear array } \\
(L V 7.5 / 60 / 96 Z)\end{array}$ & single & - & 8 & 50 \\
\hline Giannakou 2011 [33] & $\begin{array}{c}\text { SSD-4000 } \\
\text { Hitachi-Aloka (Tokyo, JP) }\end{array}$ & $42 \mathrm{~mm}$, linear array & single & $\begin{array}{l}\text { lightweight foam fixation, } \\
\text { hook-and-loop straps, elastic bandage }\end{array}$ & 7.5 & 43 \\
\hline Cronin 2011 [22] & $\begin{array}{l}\text { Echo Blaster } 128 \\
\text { Telemed (Vilnius, LT) }\end{array}$ & $\begin{array}{l}60 \mathrm{~mm} \text {, linear array } \\
96 \text { channels }\end{array}$ & single & compressive bandage & 7 & 80 \\
\hline Lichtwark 2007 [21] & $\begin{array}{l}\text { Echo Blaster } 128 \mathrm{UAB} \\
\text { Telemed (Vilnius, } L T \text { ) }\end{array}$ & $\begin{array}{l}60 \mathrm{~mm} \text {, linear array } \\
128 \text { channels }\end{array}$ & single & $\begin{array}{c}\text { bandage } \\
\text { Coban }(3 M, \text { St. Paul, MN, USA) }\end{array}$ & 7 & 25 \\
\hline Ishikawa 2007a [23] & $\begin{array}{l}\text { SSD-5500m and Prosound } \alpha 10 \\
\text { Hitachi-Aloka (Tokyo, JP) }\end{array}$ & $60 \mathrm{~mm}$, linear array & single & $\begin{array}{c}\text { polystyrene supporting } \\
\text { device (130 g incl. probe-end) }\end{array}$ & 10 & 96-196 \\
\hline Ishikawa $2007 b$ [34] & $\begin{array}{c}\text { SSD-5500 } \\
\text { Hitachi-Aloka (Tokyo, JP) }\end{array}$ & $60 \mathrm{~mm}$, linear array & single & - & 7.5 & 96 \\
\hline Lichtwark 2006 [8] & $\begin{array}{l}\text { Echo Blaster } 128 \text { UAB } \\
\text { Telemed (Vilnius, LT) }\end{array}$ & $\begin{array}{c}60 \mathrm{~mm} \text {, linear array } \\
128 \text { channels }\end{array}$ & single & bandage & 7 & 25 \\
\hline
\end{tabular}


With the exception of Bohm et al. [7], all the studies considered in this review investigated muscle functions in plantarflexors of the lower limbs (Figure 1). First, the MTUs in plantarflexors are main contributors to human locomotion [35-37]. Second, muscle fascicle lengths in the soleus (SO), medial gastrocnemius (MG), lateral gastrocnemius (LG) and tibialis posterior (TP) rarely exceed the size of the linear transducer array at any contraction mode. Thus, muscle fascicle length changes can be measured in full over the entire gait cycle. Bohm et al. [7] investigated fascicle behavior in the longer vastus lateralis (VL) using a larger 192-channel linear array probe $(100 \mathrm{~mm})$ by accepting lower frame rates of $43 \mathrm{~Hz}$. However, if fascicle length exceeds the covered area, extrapolation methods must be used to estimate fascicle lengths.

Usually, a US transducer tracks either the muscle fascicle or the muscle-tendon junction (MTJ) movement while 3d motion capture registers the position of the related body segment(s). By combining these measurements, the MTU length can then be estimated, for example, by the method proposed by Hawkins et al. [38]. Others transfer the measured data into a virtual environment (e.g., OpenSim $[39,40]$ ) where a musculoskeletal model is scaled to the body anthropometry of the test subject [41-45]. Regarding the calculation of MTU lengths for every time increment, the earlier study of Lichtwark et al. [21] used the estimation method proposed by Grieve et al. [46] to calculate MG MTU lengths. However, there is common consensus in favor of the methodology proposed by Fukunaga et al. [47] to estimate serial-elastic-element (SEE) lengths in the reviewed articles.

Table 2. Mean fascicle velocities and mean calculated frame-rate-dependent parameters for full stance or stride phases. Note that not all studies examined provided sufficient information (e.g., only statistical values) to extract all parameters for the investigated time intervals.

\begin{tabular}{|c|c|c|c|c|c|c|c|c|c|}
\hline Study & No. Subj. & Locomotion Speed & Phase & Fascicle & $\Delta t^{1}(s)$ & $\Delta \mathrm{L}_{\mathrm{tis}}{ }^{2}(\mathrm{~m})$ & $\mathrm{v}_{\text {tisMean }}{ }^{3}(\mathrm{~m} / \mathrm{s})$ & $\mathrm{dpf}_{\mathrm{t}}{ }^{4}(\mathrm{~m})$ & $\mathrm{fpt}^{5}(-)(\mathrm{fps}(\mathrm{Hz}))$ \\
\hline Ishikawa 2007a [23] & 8 & $\begin{array}{c}6.5 \mathrm{~m} / \mathrm{s} \\
\text { TM run }\end{array}$ & stance & $\mathrm{MG}^{7}$ & $149 \pm 17 \times 10^{-3}$ & $12.5 \times 10^{-3}$ & $83.89 \times 10^{-3}$ & $\begin{array}{l}0.87 \times 10^{-3} \\
0.49 \times 10^{-3}\end{array}$ & $\begin{array}{c}14(96) \\
25(169)\end{array}$ \\
\hline Suzuki 2019 [20] & 7 & $\begin{array}{c}5 \mathrm{~m} / \mathrm{s} \\
\text { TM run, forefoot strike }\end{array}$ & stance & MG & $160 \times 10^{-3}$ & $9 \times 10^{-3}$ & $56.25 \times 10^{-3}$ & $0.51 \times 10^{-3}$ & $17(110)$ \\
\hline Swinnen 2018 [25] & 19 & $\begin{array}{c}3.88 \mathrm{~m} / \mathrm{s} \\
\text { TM run, rearfoot strike }\end{array}$ & stance & MG & - & $16 \pm 4.1 \times 10^{-3}$ & $72.3 \pm 20.3 \times 10^{-3}$ & $0.84 \times 10^{-3}$ & $19(86)$ \\
\hline Sano $2015 a$ [28] & 22 & $\begin{array}{c}3.86 \mathrm{~m} / \mathrm{s} \\
\text { TM run }\end{array}$ & stance & MG & $\begin{array}{l}205 \pm 23 \times 10^{-3} \\
208 \pm 10 \times 10^{-3}\end{array}$ & $\begin{array}{l}3.51 \times 10^{-3} \\
6.64 \times 10^{-3}\end{array}$ & $\begin{array}{l}17.12 \times 10^{-3} \\
31.92 \times 10^{-3}\end{array}$ & $\begin{array}{l}0.29 \times 10^{-3} \\
0.55 \times 10^{-3}\end{array}$ & $\begin{array}{l}11(58) \\
12(65)\end{array}$ \\
\hline Cronin 2016 [27] & 11 & $\begin{array}{c}3-3.8 \dot{3} \mathrm{~m} / \mathrm{s} \\
\text { TM run }\end{array}$ & stance & $\begin{array}{l}\mathrm{SO}^{8} \\
\mathrm{MG}\end{array}$ & - & $\begin{array}{c}3 \times 10^{-3} \\
4.63 \times 10^{-3}\end{array}$ & $\begin{array}{l}29.09 \times 10^{-3} \\
65.45 \times 10^{-3}\end{array}$ & $\begin{array}{l}0.69 \times 10^{-3} \\
1.55 \times 10^{-3}\end{array}$ & $\begin{array}{l}4(42) \\
2(42)\end{array}$ \\
\hline Cronin 2013 [31] & 10 & $\begin{array}{l}2.8 \dot{3} \pm 0.47 \mathrm{~m} / \mathrm{s} \\
\text { OG run }{ }^{9}, \text { barefoot }\end{array}$ & stance & $\begin{array}{l}\text { SO } \\
\text { MG }\end{array}$ & $254 \times 10^{-3}$ & $\begin{array}{c}3.25 \times 10^{-3} \\
12.05 \times 10^{-3}\end{array}$ & $\begin{array}{l}12.78 \times 10^{-3} \\
47.42 \times 10^{-3}\end{array}$ & $\begin{array}{l}0.16 \times 10^{-3} \\
0.59 \times 10^{-3}\end{array}$ & $\begin{array}{l}20(80) \\
20(80)\end{array}$ \\
\hline Lichtwark 2006 [8] & 6 & $\begin{array}{c}2.77 \mathrm{~m} / \mathrm{s} \\
\text { TM run, incline }\end{array}$ & stance & MG & $288 \times 10^{-3}$ & $12.84 \times 10^{-3}$ & $44.60 \times 10^{-3}$ & $1.78 \times 10^{-3}$ & $7(25)$ \\
\hline Ishikawa $2007 b$ [34] & 7 & $\begin{array}{c}2.74 \pm 0.21 \mathrm{~m} / \mathrm{s} \\
\text { OG run }\end{array}$ & stance & MG & $296 \pm 28.4 \times 10^{-3}$ & $16 \times 10^{-3}$ & $54.05 \times 10^{-3}$ & $0.56 \times 10^{-3}$ & $28(96)$ \\
\hline Lichtwark 2007 [21] & 6 & $\begin{array}{c}2.08 \mathrm{~m} / \mathrm{s} \\
\text { TM run }\end{array}$ & stance & MG & $312 \times 10^{-3}$ & $14.73 \times 10^{-3}$ & $47.20 \times 10^{-3}$ & $1.89 \times 10^{-3}$ & $7(25)$ \\
\hline Farris 2012 [32] & 10 & $\begin{array}{c}3.25 \mathrm{~m} / \mathrm{s} \\
\text { TM run }\end{array}$ & stride & MG & - & $13 \pm 2 \times 10^{-3}$ & $28.0 \pm 4 \times 10^{-3}$ & $0.56 \times 10^{-3}$ & $23(50)$ \\
\hline
\end{tabular}

${ }^{1} \Delta \mathrm{t}$-time interval; ${ }^{2} \Delta \mathrm{L}_{\mathrm{tis}}$-mean tissue displacement; ${ }^{3} \mathrm{v}_{\text {tissMean }}$-mean tissue velocity; ${ }^{4} \mathrm{dpf}_{\mathrm{t}}$-mean covered distance per frame; ${ }^{5} \mathrm{fpt}$-number of recorded frames at selected frame rate; ${ }^{6} \mathrm{TM}$ run-treadmill run; ${ }^{7} \mathrm{MG}-\mathrm{medial}$ gastrocnemius; ${ }^{8} \mathrm{SO}-$ soleus; ${ }^{9}$ OG run-overground run.

Across all surveyed studies US images were recorded at an average frame rate of $80 \mathrm{~Hz}$. Nearly half of the studies investigated human locomotion at average speeds of $3 \mathrm{~ms}^{-1}$, and recorded US images at average frame rates of $60 \mathrm{~Hz}$. Studies that investigated higher locomotion speeds recorded images at frame rates up to $100 \mathrm{~Hz}$ and more. Particularly, it should be noted that all studies showed spatio-temporal resolutions in the millimeter range. 
Table 3. Mean fascicle velocities and mean calculated frame-rate-dependent parameters for critical time intervals in the gait cycle where maximum tissue velocities occurred. Note that not all studies examined provided sufficient information (e.g., only statistical values) to extract all parameters for the investigated time intervals.

\begin{tabular}{|c|c|c|c|c|c|c|c|c|c|}
\hline Study & No. Subj. & Locomotion Speed & Phase & Fascicle & $\Delta t^{1}(s)$ & $\Delta \mathrm{L}_{\mathrm{tis}}{ }^{2}(\mathrm{~m})$ & $\mathrm{v}_{\text {tisMean }}{ }^{3}(\mathrm{~m} / \mathrm{s})$ & $\mathrm{dpf}_{\mathrm{t}}{ }^{4}(\mathrm{~m})$ & $\mathrm{fpt}^{5}(-)(\mathrm{fps}(\mathrm{Hz}))$ \\
\hline \multirow{3}{*}{ Lai 2018 [24] } & \multirow{3}{*}{10} & & stance & $\mathrm{SO}^{7}$ & \multirow{3}{*}{-} & $2.03 \times 10^{-3}$ & $68.34 \times 10^{-3}$ & $0.85 \times 10^{-3}$ & $2(80)$ \\
\hline & & $5 \mathrm{~m} / \mathrm{s}$ & (ankle moment & $\mathrm{MG}^{8}$ & & $2.31 \times 10^{-3}$ & $75.98 \times 10^{-3}$ & $0.94 \times 10^{-3}$ & $2(80)$ \\
\hline & & TM run ${ }^{6}$ & decline) & $\mathrm{LG}^{9}$ & & $2.51 \times 10^{-3}$ & $56,7 \times 10^{-3}$ & $0.70 \times 10^{-3}$ & $3(80)$ \\
\hline Swinnen 2018 [25] & 19 & $\begin{array}{c}3.8 \dot{8} \mathrm{~m} / \mathrm{s} \\
\text { TM run, rearfoot strike }\end{array}$ & $\begin{array}{c}\text { stance } \\
(0 \%-30 \%)\end{array}$ & MG & - & - & $218 \times 10^{-3}$ & $2.53 \times 10^{-3}$ & $-(86)$ \\
\hline \multirow{2}{*}{ Sano 2015a [28] } & \multirow{2}{*}{22} & $3.86 \mathrm{~m} / \mathrm{s}$ & stance & \multirow{2}{*}{ MG } & $97 \pm 10 \times 10^{-3}$ & $2.20 \times 10^{-3}$ & $22.67 \times 10^{-3}$ & $0.39 \times 10^{-3}$ & $5(58)$ \\
\hline & & TM run & (push off) & & $100 \pm 9 \times 10^{-3}$ & $3.41 \times 10^{-3}$ & $34.15 \times 10^{-3}$ & $0.53 \times 10^{-3}$ & $6(65)$ \\
\hline Bohm 2018 [7] & 30 & $\begin{array}{l}3 \mathrm{~m} / \mathrm{s} \\
\text { TM run }\end{array}$ & $\begin{array}{c}\text { stance } \\
\text { (active state) }\end{array}$ & $\mathrm{VL}^{10}$ & $136 \pm 18 \times 10^{-3}$ & $8.5 \pm 8.2 \times 10^{-3}$ & $62.5 \times 10^{-3}$ & $1.45 \times 10^{-3}$ & $5(43)$ \\
\hline Lichtwark 2007 [21] & 6 & $\begin{array}{c}2.08 \mathrm{~m} / \mathrm{s} \\
T M \mathrm{run}\end{array}$ & $\begin{array}{c}\text { swing phase } \\
\mathrm{t}=0.6-0.68 \mathrm{~s} \text { (medial) }\end{array}$ & MG & $88 \times 10^{-3}$ & $13.12 \times 10^{-3}$ & $149.14 \times 10^{-3}$ & $5.96 \times 10^{-3}$ & $2(25)$ \\
\hline Maharaj 2016 [26] & 15 & $\begin{array}{c}1.9 \pm 0.1 \mathrm{~m} / \mathrm{s} \\
T M \text { walk, barefoot }\end{array}$ & $\begin{array}{c}\text { stance } \\
\text { (late) }\end{array}$ & $\mathrm{TP}^{11}$ & - & $4.5 \pm 3.4 \times 10^{-3}$ & $29.2 \pm 6.2 \times 10^{-3}$ & $0.36 \times 10^{-3}$ & $12(80)$ \\
\hline
\end{tabular}

frame rate; ${ }^{6} \mathrm{TM}$ run—treadmill run; ${ }^{7} \mathrm{SO}$ - soleus; ${ }^{8} \mathrm{MG}$ - medial gastrocnemius; ${ }^{9} \mathrm{LG}$-lateral gastrocnemius; ${ }^{10} \mathrm{VL}$-vastus lateralis; ${ }^{11} \mathrm{TP}$-tibialis posterior. 


\section{Discussion}

Muscles contract during locomotion. Thus, the activated muscle shortens and aponeuroses, and tendon(s) change in length. Thereby, the net output of an activated MTU depends on the force-velocity relation [48], the force-length relation [49], the muscle-tendon length [50], the contraction mode (e.g., eccentric, concentric, isometric contraction [51]), and contraction history effects (e.g., force enhancement and depression [52], fatigue [53], as well as tendon hysteresis effects [54]). Hence, the interaction of the whole MTU and all its respective components is responsible for the resulting movement, where the storage and release of elastic energy are also key [3-5,55].

Studying these phenomena in vivo during movement requires a wearable US research system with a wide range of view and a high spatio-temporal resolution. Currently available sensor systems are not able to record displacements of muscles, aponeuroses, and tendons simultaneously along the whole MTU, or can only do so to a limited extent. Although imaging system requirements for biomechanics applications are unique, there are several recent developments in US system design which can be leveraged.

\subsection{System Designs and Form Factors}

US imagers as used for biomechanics research (Table 1) such as the Echo Blaster (Telemed) or the ProSound (Hitachi-Aloka) are "commercial systems for research purposes". They have add-on research interfaces but cannot be reconfigured or do not provide access to transmit operations (TX) and receive operations (RX) due to hardware constraints [19]. Biomechanics researchers are thus left only with the possibilities of finding either more advantageous arrangements for bulky transducers or increasing frame rates by reducing the range of view and image quality. Opening TX operations would allow scientists to better adapt their setups (e.g., by choosing wave forms and steering or focusing the beam at certain areas). Moreover, access to raw RX data would enable the testing of new signal processing methodologies and algorithms. Hence, the development of US imaging platforms for biomechanical research should be driven by the need for more flexibility in parameter settings and access to raw imaging data. Boni et al. [19] defined three key features of open-platform US scanners:

- Customization of transmit waveform (open TX operation);

- Access to pre-beamformed raw data (open RX data-sets); and

- Ability to implement real-time imaging.

US imagers as applied in movement science work with classical US design concepts. Bulky transducer probes connect to backend systems by analog cable harnesses (Figure 3). These backend systems are powered externally via cable. They mostly have limited internal data storage to save still images for offline analysis and record images at low frame rates. All these characteristics cause obtrusive test setups for the use of US during locomotion. Currently, this impediment is handled by splitting the systems in two. The probe and its connecting cable harnesses are placed as closely as possible to the center-of-mass (CM) of the moving body parts (Figure 2) while the heavier backend system is stored securely outside the testing area. Cronin et al. [31] used a different setup by placing a 5-kg backpack containing the backend system on to the moving subject. However, load carrying affects gait [56]. Such a setup still includes a cable system that interferes with movement: coaxial cable connection between the backend system and the probe; power cable between the backend system and the grid; USB data cable between the backend system and the PC.

Transducer probes of conventional US systems are ergonomically shaped and designed to be hand-operated on patients' skin for diagnosis. In contrast, the probes of US systems in biomechanical research need to be fixed to the skin during motion (e.g., in order to guarantee reproducible image quality over several stride cycles). Probe mounting is a key task, and must be as unobtrusive as possible to avoid interfering with natural movement patterns while simultaneously ensuring stable fixation to the region of interest. The form factor of veterinary probes (Figure 2) allows the placement of transducers in closer proximity to the body. Cord exits in veterinary probes are in line with the 
linear array and therefore interfere less with moving body parts. Both characteristics reduce torque on the transducer while in motion, thus decreasing imaging errors.

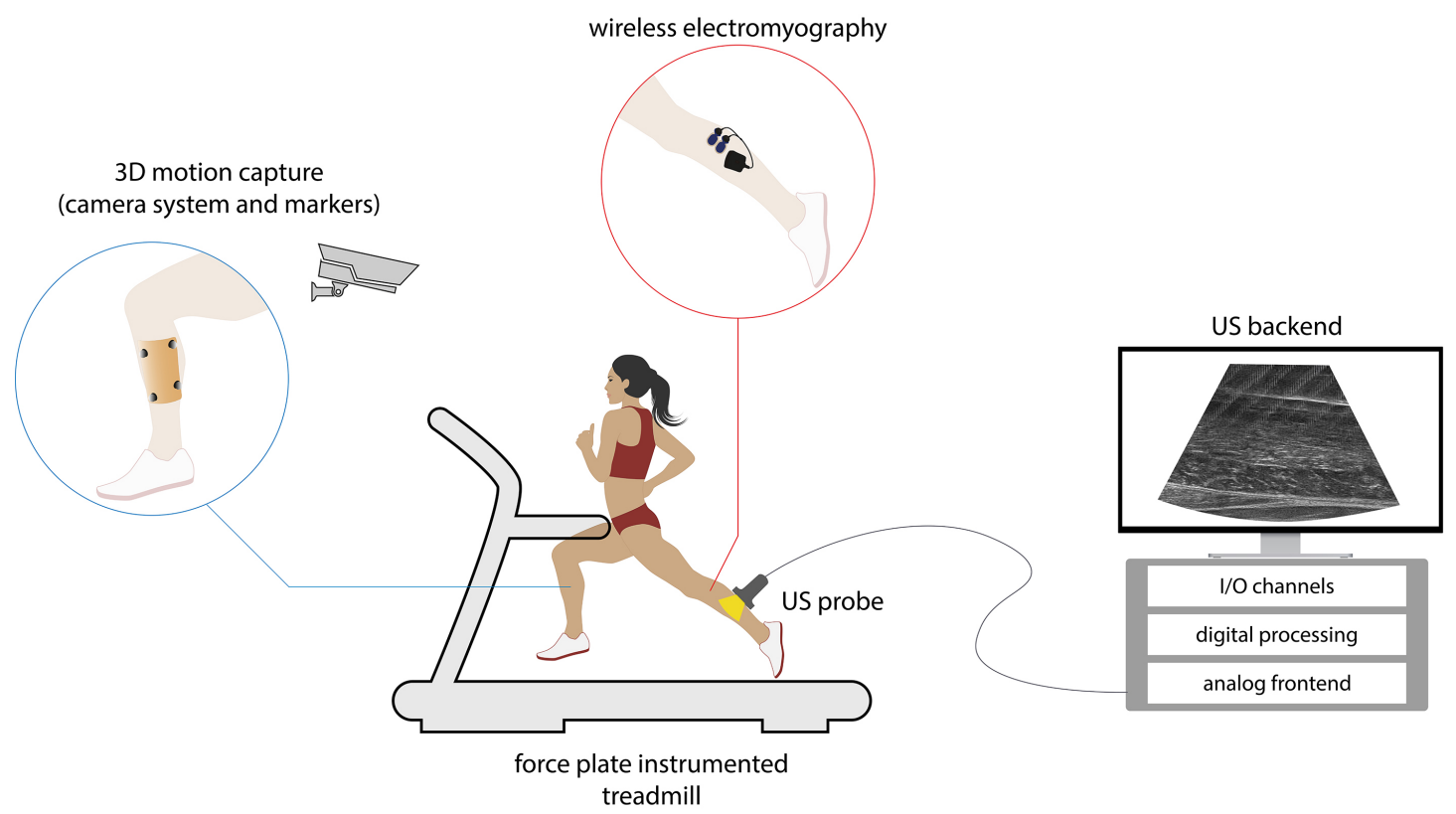

Figure 3. Movement science laboratory using ultrasound measurement during locomotion.

Movement science needs unobtrusive biomonitoring. This means that sensors are placed in close proximity to bodies and do not interfere with the actions of a subject. In terms of in-vivo biomonitoring human and animal movement, observation devices are still in early stages $[14,15,17]$. Research demands the development of more parasitic methodologies as defined by Benini et al. [57]. This implies that while US sensors will still be perceptible by test subjects, their size, weight, and structure will not seriously interfere with movement patterns. Their power consumption can range up to a maximum of a few milliwatts with the current energy density in batteries.

\subsection{Recording Muscle and Tendon Tissue Dynamics}

In anatomical images of muscles and tendons during locomotion, the movement of tissue structures (e.g., muscle fascicles) and anatomical landmarks (e.g., MTJs) are recorded. The range of view of US imagers used for biomechanical research allows the observation of tissues within a spatial range between a few millimeters up to approximately $100 \mathrm{~mm}$ [58]. A new ultrasound system class for locomotion research in humans should aim to record a range of view of at least 250 $\mathrm{mm}$. This length covers large areas of the MTU in the human plantarflexors [59-61] and allows full simultaneous imaging of its components and landmarks. These properties might change for veterinary applications, as MTUs lengths range up to $700 \mathrm{~mm}$ and more [11] in large animals.

A US imager for biomechanical research records displacements of muscles and tendons. Hence, frame rates need to be adjusted as tissue velocities rise or spatio-temporal resolution requirements for post-processing change. High-frame-rate imaging in muscle tissues has been exploited dominantly in elastography [62] or studies on cardiac muscles (e.g., pulse wave propagation) in humans $[63,64]$ and animals [65]. Deffieux et al. [66] studied in-vivo muscle contractions of the human biceps brachii at frame rates of $1500 \mathrm{~Hz}$. Their investigations achieved spatio-temporal resolutions in the micrometer range. This setup was needed to dissolve the contraction and relaxation of muscle fibers. In contrast, locomotion research works with conventional US systems (Table 1) which allow spatio-temporal resolutions in the millimeter range, as presented in Tables 2 and 3. Due to hardware constraints, frame rates are limited. Pushing them beyond $80 \mathrm{~Hz}$ with the used system platforms affects image resolutions and decreases the range of view (e.g., because scanlines are reduced). 
Lichtwark et al. [21] investigated MG fascicles at locomotion speeds of $2.08 \mathrm{~ms}^{-1}$ while capturing images at frame rates of $25 \mathrm{~Hz}$. Increasing frame rates to $150 \mathrm{~Hz}$ for imaging mean states and $250 \mathrm{~Hz}$ for imaging critical states would lead to significant improvements in spatio-temporal resolution:

- Mean states recorded at $150 \mathrm{~Hz}: \mathrm{dpf}_{\mathrm{t}}=0.31 \times 10^{-3} \mathrm{~m}$, fpt $=46$ (respectively at $25 \mathrm{~Hz}$ : $\mathrm{dpf}_{\mathrm{t}}=1.89 \times 10^{-3} \mathrm{~m}, \mathrm{fpt}=7$ );

- Critical states recorded at $250 \mathrm{~Hz}$ : $\mathrm{dpf}_{\mathrm{t}}=0.59 \times 10^{-3} \mathrm{~m}$, fpt $=21$ (respectively at $25 \mathrm{~Hz}$ : $\left.\mathrm{dpf}_{\mathrm{t}}=5.96 \times 10^{-3} \mathrm{~m}, \mathrm{fpt}=2\right)$.

In conclusion, research investigating muscle and tendon functions in vivo should aim to record images at frame rates in the kilohertz range. With the special demands of movement science (e.g., wide range of view, unobtrusiveness, mounting, etc.) and current US technologies $[67,68]$, we therefore recommend targeting spatio-temporal resolutions of at least $\mathrm{dpf}_{\mathrm{t}}=0.5 \times 10^{-3} \mathrm{~m}$. This corresponds to required frame rates of $150 \mathrm{~Hz}$ for locomotion speeds at $3 \mathrm{~ms}^{-1}$. To sufficiently record critical states during the gait cycle or higher locomotion speeds, frame rates of $250 \mathrm{~Hz}$ and above might be necessary. Findings for optical systems recording human locomotion using passive markers have shown similar requirements [69].

The ability to capture US images at very high frame rates $(100 \mathrm{~Hz}$ to $10 \mathrm{kHz})[67,70]$ is already a feature in today's high-end research systems [19], and is being implemented in large commercial devices (e.g., Aixplorer by Supersonic Imaging).

\subsection{Bringing Research Demands into System Form Factors}

Measuring the muscle and tendon functions of humans and animals during locomotion poses different technical requirements for US imagers to those for which existing systems have usually been designed. On the one hand, the need for high frame rate, wide range of view, and raw data access would be best met by state-of-the-art, high-channel-count research systems such as Vantage-256 (Verasonics), DiPhAS (Fraunhofer IBMT), SARUS [71], or ULAOP-256 [72]. To the best of our knowledge, there are not yet any handheld mobile systems available on the market that can support such high frame rates.

On the other hand, the need to move without restriction for unhindered measurements requires a free measurement setup. This rules out all the research systems mentioned above, as they consist of large heavy boxes containing the imaging systems' electronics to which transducers, power supplies, and personal computers (PCs) are connected via cables. By contrast, mobile handheld systems such as Lumify (Philips), MobiUS PE System (MobiSante), or iQ (Butterfly Network) consist of a digital US probe connected to a smartphone. These are light enough to be carried by the subject. However, the digital transducer probe itself is bulky and the transducer opening is ill-placed to attach the probe to the body without interfering with measurements. Moreover, these systems typically do not provide access to raw US data and have processing restrictions (e.g., limited frame rates) due to thermal power constraints [73]. One main issue for the inclusion of high-frame-rate imaging into a system form factor, while meeting the constraints of movement science-and the constraints of portable systems in general-is the huge size of raw image data $(>100 \mathrm{MB})$ and the data rates $(>10 \mathrm{~GB} / \mathrm{s})$ that sensors produce for processing.

Recent developments in US system design [13] also combine the flexibility of software-defined ultrafast imagers with cost-efficient and miniaturized digital transducers [74]. Current system design trends [19] such as extended numbers of channel systems, hybrid computation approaches (hardware-accelerated vs. software-defined systems), and system design partitioning can contribute to overcoming impediments in biomechanics applications to image whole MTUs at high frame rates.

\section{Conclusions}

This review investigated the current state of applying ultrasound (US) as a research tool to study muscle and tendon functions during locomotion. In terms of biomonitoring muscle and tendon dynamics, science is still in its early stages as US observation devices do not meet the requirements to 
record tissue structures sufficiently. Biomechanical research demands the development of unobtrusive, wide range of view, and ultrafast US imaging systems. We suggest the consideration of the following recommendations during the development of new US sensor systems for movement science:

- Research studying muscle and tendon functions should aim to record images at frame rates in the kilohertz range.

- Frame rates of at least $150 \mathrm{~Hz}$ should be used to reach spatio-temporal resolutions of $\mathrm{dpf}_{\mathrm{t}}=0.5 \times 10^{-3} \mathrm{~m}$. To record tissues at critical states or higher locomotion speeds, frame rates of $250 \mathrm{~Hz}$ or more might be necessary to reach the same spatio-temporal resolution.

- The range of view should cover the area of whole muscle and tendon complexes. To record muscle and tendon dynamics sufficiently, we recommend a range of view for US imaging devices of at least $250 \mathrm{~mm}$. This might be substantially larger $(700 \mathrm{~mm}$ and more) for research on large animals.

- The development of new US imaging solutions in movement science should be driven by the need for more flexibility in parameter settings and access to raw imaging data (open US imaging platforms as defined by Boni et al. [19]).

- The design of a new US system class targeting biomechanical applications must be as unobtrusive as possible in order to avoid interfering with natural movement patterns while simultaneously assuring stable probe fixation to the region of interest.

Hybrid design approaches comprising mobile, ultrafast US hardware and advanced image processing create opportunities to solve previous shortcomings. By following these development guidelines, future US imagers could help to expand the existing knowledge of human and animal movement.

Author Contributions: Conceptualization, C.L.; investigation, C.L.; resources, C.B., M.T., L.B., and C.P.; writing-original draft preparation, C.L., P.A.H., and C.P.; writing-review and editing, C.L., P.A.H., and H.P.; visualization, C.L.; supervision, C.B., L.B., C.P., and M.T.

Funding: This research received no external funding.

Acknowledgments: The authors would like to thank Martin Sust and Helmut Gausterer for their insightful feedback.

Conflicts of Interest: The authors declare no conflict of interest.

\section{Abbreviations}

The following abbreviations are used in this manuscript:

CM center-of-mass

LG lateral gastrocnemius

MG medial gastrocnemius

MTJ muscle-tendon junction

OG overground

$\mathrm{RF}$ radio frequency

$\mathrm{RX}$ receive operation

SEE serial elastic element

SFDF superficial digital flexor

SO soleus

SSC stretch-shortening cycle

TM treadmill

TP tibialis posterior

TS triceps surae

TX transmit operation

US ultrasound

VL vastus lateralis 


\section{Appendix A}

A systematic search (Figure A1) to identify studies that investigated muscles and tendons directly, in vivo, during locomotion using US included the following databases: SCOPUS, Medline, Google Scholar. The database search revealed 172 items, and 4 other sources were added. After title and abstract screening, 29 full-text articles were considered eligible. Twelve were excluded as they did not meet the criteria (locomotion; locomotion speed $>1.9 \mathrm{~ms}^{-1}$; healthy subjects; publication in English). In conclusion, this review covers 17 studies (Table 1).

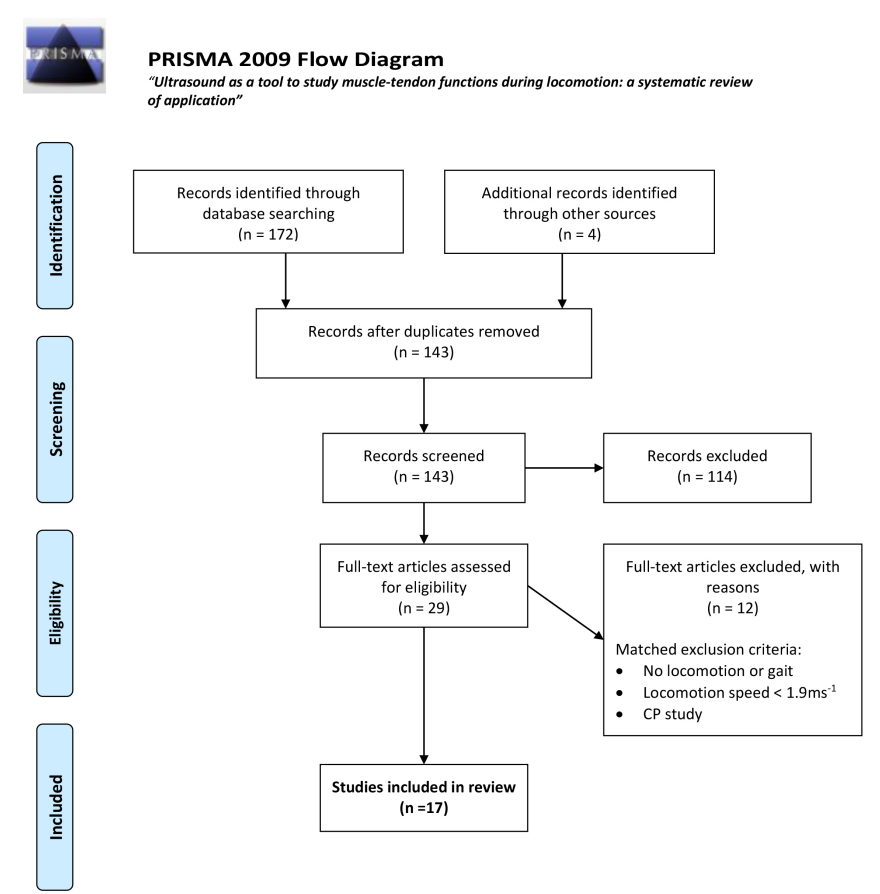

Figure A1. The present review followed the PRISMA Flow Diagram [18].

\section{References}

1. Komi, P.V. Stretch-shortening cycle: A powerful model to study normal and fatigued muscle. J. Biomech. 2000, 33, 1197-1206. [CrossRef]

2. Alexander, R.M. Energy-saving mechanisms in walking and running. J. Exp. Biol. 1991, 160, 55-69.

3. Alexander, R.M.; Bennet-Clark, H.C. Storage of elastic strain energy in muscle and other tissues. Nature 1977, 265, 114-117. [CrossRef]

4. Lichtwark, G.A.; Wilson, A.M. In vivo mechanical properties of the human Achilles tendon during one-legged hopping. J. Exp. Biol. 2005, 208, 4715-4725. [CrossRef]

5. Penasso, H.; Thaller, S. Determination of individual knee-extensor properties from leg extensions and parameter identification. Math. Comput. Modell. Dyn. Syst. 2017, 23, 416-438. [CrossRef]

6. Barber, L.; Carty, C.; Modenese, L.; Walsh, J.; Boyd, R.; Lichtwark, G. Medial gastrocnemius and soleus muscle-tendon unit, fascicle, and tendon interaction during walking in children with cerebral palsy. Dev. Med. Child Neurol. 2017, 59, 843-851. [CrossRef]

7. Bohm, S.; Marzilger, R.; Mersmann, F.; Santuz, A.; Arampatzis, A. Operating length and velocity of human vastus lateralis muscle during walking and running. Sci. Rep. 2018, 8, 5066. [CrossRef]

8. Lichtwark, G.A.; Wilson, A.M. Interactions between the human gastrocnemius muscle and the Achilles tendon during incline, level and decline locomotion. J. Exp. Biol. 2006, 209, 4379-4388. [CrossRef]

9. Roberts, T.J.; Marsh, R.L.; Weyand, P.G.; Taylor, C.R. Muscular force in running turkeys: The economy of minimizing work. Science 1997, 275, 1113-1115. [CrossRef]

10. Dimery, N.J.; Alexander, R.M.; Ker, R.F. Elastic extension of leg tendons in the locomotion of horses (Equus caballus). J. Zool. 1986, 210, 415-425. [CrossRef] 
11. Alexander, R.M.; Maloiy, G.M.O.; Ker, R.F.; Jayes, A.S.; Warui, C.N. The role of tendon elasticity in the locomotion of the camel (Camelus dromedarius). J. Zool. 1982, 198, 293-313. [CrossRef]

12. Thaller, S.; Penasso, H. Muscle mechanics. In Modelling and Simulation in Sport and Exercise; Routledge: London, UK, 2018; pp. 22-49. [CrossRef]

13. Hager, P.A. Design of Fully-Digital Medical Ultrasound Imaging Systems. Ph.D. Thesis, ETH, Zürich, Switzerland, 2019.

14. Lichtwark, G. Ultrasound Technology for Examining the Mechanics of the Muscle, Tendon, and Ligament. In Handbook of Human Motion; Bertram, M., Wolf, S.I., Gert-Peter, B., Zhigang, D., Andrew, M., Freeman, M., Scott, S.W., Eds.; Springer International Publishing: Cham, Switzerland, 2017; pp. 1-20.

15. Seynnes, O.R.; Bojsen-Møller, J.; Albracht, K.; Arndt, A.; Cronin, N.J.; Finni, T.; Magnusson, S.P. Ultrasound-based testing of tendon mechanical properties: A critical evaluation. Eur. J. Appl. Physiol. 2015, 118, 133-141. [CrossRef] [PubMed]

16. Andriacchi, T.P.; Alexander, E.J. Studies of human locomotion: Past, present and future. J. Biomech. 2000, 33, 1217-1224. [CrossRef]

17. Cronin, N.J.; Lichtwark, G. The use of ultrasound to study muscle-tendon function in human posture and locomotion. Gait Posture 2013, 37, 305-312. [CrossRef] [PubMed]

18. Moher, D.; Liberati, A.; Tetzlaff, J.; Altman, D.G.; Group, T.P. Preferred reporting items for systematic reviews and meta-analyses: The PRISMA statement. PLoS Med. 2009, 6, e1000097. [CrossRef] [PubMed]

19. Boni, E.; Yu, A.C.H.; Freear, S.; Jensen, J.A.; Tortoli, P. Ultrasound Open Platforms for Next-Generation Imaging Technique Development. IEEE Trans. Ultrason. Ferroelectr. Freq. Control 2018, 65, 1078-1092. [CrossRef]

20. Suzuki, T.; Ogane, R.; Yaeshima, K.; Kinugasa, R. Forefoot running requires shorter gastrocnemius fascicle length than rearfoot running. J. Sports Sci. 2019, 1-9. [CrossRef] [PubMed]

21. Lichtwark, G.; Bougoulias, K.; Wilson, A. Muscle fascicle and series elastic element length changes along the length of the human gastrocnemius during walking and running. J. Biomech. 2007, 40, 157-164. [CrossRef]

22. Cronin, N.J.; Carty, C.P.; Barrett, R.S.; Lichtwark, G. Automatic tracking of medial gastrocnemius fascicle length during human locomotion. J. Appl. Physiol. 2011, 111, 1491-1496. [CrossRef]

23. Ishikawa, M.; Komi, P.V. The role of the stretch reflex in the gastrocnemius muscle during human locomotion at various speeds. J. Appl. Physiol. 2007, 103, 1030-1036. [CrossRef]

24. Lai, A.K.M.; Lichtwark, G.A.; Schache, A.G.; Pandy, M.G. Differences in in vivo muscle fascicle and tendinous tissue behavior between the ankle plantarflexors during running. Scand. J. Med. Sci. Sports 2018, 28, 1828-1836. [CrossRef] [PubMed]

25. Swinnen, W.; Hoogkamer, W.; Delabastita, T.; Aeles, J.; De Groote, F.; Vanwanseele, B. Effect of habitual foot-strike pattern on the gastrocnemius medialis muscle-tendon interaction and muscle force production during running. Eur. J. Appl. Physiol. 2018, 126, 708-716. [CrossRef] [PubMed]

26. Maharaj, J.N.; Cresswell, A.G.; Lichtwark, G.A. The mechanical function of the tibialis posterior muscle and its tendon during locomotion. J. Biomech. 2016, 49, 3238-3243. [CrossRef] [PubMed]

27. Cronin, N.J.; Hanley, B.; Bissas, A. Mechanical and neural function of triceps surae in elite racewalking. J. Appl. Physiol. 2016, 121, 101-105. [CrossRef] [PubMed]

28. Sano, K.; Nicol, C.; Akiyama, M.; Kunimasa, Y.; Oda, T.; Ito, A.; Locatelli, E.; Komi, P.V.; Ishikawa, M. Can measures of muscle-tendon interaction improve our understanding of the superiority of Kenyan endurance runners? Eur. J. Appl. Physiol. 2015, 115, 849-859. [CrossRef] [PubMed]

29. Lai, A.; Lichtwark, G.A.; Schache, A.G.; Lin, Y.C.; Brown, N.A.T.; Pandy, M.G. In vivo behavior of the human soleus muscle with increasing walking and running speeds. J. Appl. Physiol. 2015, 118, 1266-1275. [CrossRef] [PubMed]

30. Sano, K.; Akiyama, M.; Hoffren-Mikkola, M.; Ito, A.; Komi, P.V.; Ishikawa, M. Age-specific neuromuscular interaction during elderly habitual running. Acta Physiol. 2015, 215, 79-88. [CrossRef]

31. Cronin, N.J.; Finni, T. Treadmill versus overground and barefoot versus shod comparisons of triceps surae fascicle behaviour in human walking and running. Gait Posture 2013, 38, 528-533. [CrossRef]

32. Farris, D.J.; Sawicki, G.S. Human medial gastrocnemius force-velocity behavior shifts with locomotion speed and gait. Proc. Natl. Acad. Sci. USA 2012, 109, 977-982. [CrossRef]

33. Giannakou, E.; Aggeloussis, N.; Arampatzis, A. Reproducibility of gastrocnemius medialis muscle architecture during treadmill running. J. Electromyogr. Kinesiol. 2011, 21, 1081-1086. [CrossRef] 
34. Ishikawa, M.; Pakaslahti, J.; Komi, P. Medial gastrocnemius muscle behavior during human running and walking. Gait Posture 2007, 25, 380-384. [CrossRef] [PubMed]

35. Pandy, M.G.; Andriacchi, T.P. Muscle and joint function in human locomotion. Annu. Rev. Biomed. Eng. 2010, 12, 401-433. [CrossRef] [PubMed]

36. Hamner, S.R.; Delp, S.L. Muscle contributions to fore-aft and vertical body mass center accelerations over a range of running speeds. J. Biomech. 2013, 46, 780-787. [CrossRef] [PubMed]

37. Ellis, R.G.; Sumner, B.J.; Kram, R. Muscle contributions to propulsion and braking during walking and running: Insight from external force perturbations. Gait Posture 2014, 40, 594-599. [CrossRef] [PubMed]

38. Hawkins, D.; Hull, M. A method for determining lower extremity muscle-tendon lengths during flexion/extension movements. J. Biomech. 1990, 23, 487-494. [CrossRef]

39. Delp, S.L.; Anderson, F.C.; Arnold, A.S.; Loan, P.; Habib, A.; John, C.T.; Guendelman, E.; Thelen, D.G. OpenSim: Open-Source Software to Create and Analyze Dynamic Simulations of Movement. IEEE Trans. Biomed. Eng. 2007, 54, 1940-1950. [CrossRef]

40. Seth, A.; Hicks, J.L.; Uchida, T.K.; Habib, A.; Dembia, C.L.; Dunne, J.J.; Ong, C.F.; DeMers, M.S.; Rajagopal, A.; Millard, M.; et al. OpenSim: Simulating musculoskeletal dynamics and neuromuscular control to study human and animal movement. PLoS Comput. Biol. 2018, 14, e1006223. [CrossRef] [PubMed]

41. Delp, S.; Loan, J.; Hoy, M.; Zajac, F.; Topp, E.; Rosen, J. An interactive graphics-based model of the lower extremity to study orthopaedic surgical procedures. IEEE Trans. Biomed. Eng. 1990, 37, 757-767. [CrossRef]

42. Lewis, G.S.; Kirby, K.A.; Piazza, S.J. Determination of subtalar joint axis location by restriction of talocrural joint motion. Gait Posture 2007, 25, 63-69. [CrossRef]

43. Arnold, E.M.; Ward, S.R.; Lieber, R.L.; Delp, S.L. A model of the lower limb for analysis of human movement. Ann. Biomed. Eng. 2010, 38, 269-279. [CrossRef]

44. Hamner, S.R.; Seth, A.; Delp, S.L. Muscle contributions to propulsion and support during running. J. Biomech. 2010, 43, 2709-2716. [CrossRef] [PubMed]

45. Dorn, T.W.; Schache, A.G.; Pandy, M.G. Muscular strategy shift in human running: Dependence of running speed on hip and ankle muscle performance. J. Exp. Biol. 2012, 215, 1944-1956. [CrossRef]

46. Grieve, D.W.; Pheasant, S.; Cavanagh, P. Prediction of gastrocnemius length from knee and ankle joint posture. Biomechanics 1978, VI-A, 405-412.

47. Fukunaga, T.; Kubo, K.; Kawakami, Y.; Fukashiro, S.; Kanehisa, H.; Maganaris, C.N. In vivo behaviour of human muscle tendon during walking. Proc. R. Soc. Lond. Ser. B Biol. Sci. 2001, 268, 229-233. [CrossRef] [PubMed]

48. Hill, A.V. The Heat of Shortening and the Dynamic Constants of Muscle. Proc. R. Soc. Lond. Ser. B Biol. Sci. 1938, 126, 136-195. [CrossRef]

49. Gordon, A.M.; Huxley, A.F.; Julian, F.J. The variation in isometric tension with sarcomere length in vertebrate muscle fibres. J. Physiol. 1966, 184, 170-192. [CrossRef]

50. Raiteri, B.J.; Cresswell, A.G.; Lichtwark, G.A. Muscle-tendon length and force affect human tibialis anterior central aponeurosis stiffness in vivo. Proc. Natl. Acad. Sci. USA 2018, 115, E3097-E3105. [CrossRef]

51. Herzog, W. The mysteries of eccentric muscle action. J. Sport Health Sci. 2018, 7, 253-254. [CrossRef]

52. Herzog, W.; Leonard, T.R. Force enhancement following stretching of skeletal muscle: A new mechanism. J. Exp. Biol. 2002, 205, 1275-1283.

53. Penasso, H.; Thaller, S. Model-based analysis of fatigued human knee extensors. Eur. J. Appl. Physiol. 2018, 118, 1447-1461. [CrossRef]

54. Nuri, L.; Obst, S.J.; Newsham-West, R.; Barrett, R.S. Regional three-dimensional deformation of human Achilles tendon during conditioning. Scand. J. Med. Sci. Sports 2017, 27, 1263-1272. [CrossRef] [PubMed]

55. Penasso, H. The Effect of Fatigue on Identified Human Neuromuscular Parameters. Ph.D. Thesis, University of Graz, Graz, Austria, 2018.

56. Ahmad, H.N.; Barbosa, T.M. The effects of backpack carriage on gait kinematics and kinetics of schoolchildren. Sci. Rep. 2019, 9, 3364. [CrossRef] [PubMed]

57. Benini, L.; Farella, E.; Guiducci, C. Wireless sensor networks: Enabling technology for ambient intelligence. Microelectron. J. 2006, 37, 1639-1649. [CrossRef]

58. Loram, I.D.; Maganaris, C.N.; Lakie, M. Use of ultrasound to make noninvasive in vivo measurement of continuous changes in human muscle contractile length. J. Appl. Physiol. 2006, 100, 1311-1323. [CrossRef] 
59. Pandy, M.G.; Zajac, F.E.; Sim, E.; Levine, W.S. An optimal control model for maximum-height human jumping. J. Biomech. 1990, 23, 1185-1198. [CrossRef]

60. Kawakami, Y.; Ichinose, Y.; Fukunaga, T. Architectural and functional features of human triceps surae muscles during contraction. J. Appl. Physiol. 1998, 85, 398-404. [CrossRef] [PubMed]

61. Rome, K.; McNair, P. Management of Chronic Conditions in the Foot and Lower Leg; Churchill Livingstone: London, UK, 2015; p. 259. [CrossRef]

62. Tanter, M.; Bercoff, J.; Sandrin, L.; Fink, M. Ultrafast compound imaging for 2-D motion vector estimation: Application to transient elastography. IEEE Trans. Ultrason. Ferroelectr. Freq. Control 2002, 49, 1363-1374. [CrossRef]

63. Wang, S.; Lee, W.N.; Provost, J.; Luo, J.; Konofagou, E. A composite high-frame-rate system for clinical cardiovascular imaging. IEEE Trans. Ultrason. Ferroelectr. Freq. Control 2008, 55, 2221-2233. [CrossRef]

64. Papadacci, C.; Pernot, M.; Couade, M.; Fink, M.; Tanter, M. High-contrast ultrafast imaging of the heart. IEEE Trans. Ultrason. Ferroelectr. Freq. Control 2014, 61, 288-301. [CrossRef]

65. Couade, M.; Pernot, M.; Tanter, M.; Messas, E.; Bel, A.; Ba, M.; Hagege, A.A.; Fink, M. Ultrafast imaging of the heart using circular wave synthetic imaging with phased arrays. In Proceedings of the 2009 IEEE International Ultrasonics Symposium, Rome, Italy, 20-23 September 2009; pp. 515-518. [CrossRef]

66. Deffieux, T.; Gennisson, J.L.; Tanter, M.; Fink, M.; Nordez, A. Ultrafast imaging of in vivo muscle contraction using ultrasound. Appl. Phys. Lett. 2006, 89, 184107. [CrossRef]

67. Tanter, M.; Fink, M. Ultrafast imaging in biomedical ultrasound. IEEE Trans. Ultrason. Ferroelectr. Freq. Control 2014, 61, 102-119. [CrossRef] [PubMed]

68. Boni, E.; Bassi, L.; Dallai, A.; Meacci, V.; Ramalli, A.; Scaringella, M.; Guidi, F.; Ricci, S.; Tortoli, P. A real-time beamformer for high frame rate ultrasound imaging. In Proceedings of the 2016 IEEE International Ultrasonics Symposium (IUS), Tours, France, 18-21 September 2016; pp. 1-4. [CrossRef]

69. Song, M.H.; Godøy, R.I. How fast is your body motion? Determining a sufficient frame rate for an optical motion tracking system using passive markers. PLoS ONE 2016, 11, e0150993. [CrossRef] [PubMed]

70. Jensen, J.A.; Nikolov, S.I.; Gammelmark, K.L.; Pedersen, M.H. Synthetic aperture ultrasound imaging. Ultrasonics 2006, 44, e5-e15. [CrossRef] [PubMed]

71. Jensen, J.A.; Holten-Lund, H.; Nilsson, R.T.; Hansen, M.; Larsen, U.D.; Domsten, R.P.; Tomov, B.G.; Stuart, M.B.; Nikolov, S.I.; Pihl, M.J.; et al. SARUS: A synthetic aperture real-time ultrasound system. IEEE Trans. Ultrason. Ferroelectr. Freq. Control 2013, 60, 1838-1852. [CrossRef] [PubMed]

72. Boni, E.; Bassi, L.; Dallai, A.; Guidi, F.; Meacci, V.; Ramalli, A.; Ricci, S.; Tortoli, P. ULA-OP 256: A 256-channel open scanner for development and real-time implementation of new ultrasound methods. IEEE Trans. Ultrason. Ferroelectr. Freq. Control 2016, 63, 1488-1495. [CrossRef] [PubMed]

73. Hager, P.A.; Speicher, D.; Degel, C.; Benini, L. UltraLight: An ultrafast imaging platform based on a digital 64-channel ultrasound probe. In Proceedings of the 2017 IEEE International Ultrasonics Symposium (IUS), Washington, DC, USA, 6-9 September 2017; pp. 1-5. [CrossRef]

74. Hager, P.A.; Risser, C.; Weber, P.K.; Benini, L. LightProbe: A 64-channel programmable ultrasound transducer head with an integrated front-end and a $26.4 \mathrm{~Gb} / \mathrm{s}$ optical link. In Proceedings of the 2017 IEEE International Symposium on Circuits and Systems (ISCAS), Baltimore, MD, USA, 28-31 May 2017; pp. 1-4. [CrossRef]

(C) 2019 by the authors. Licensee MDPI, Basel, Switzerland. This article is an open access article distributed under the terms and conditions of the Creative Commons Attribution (CC BY) license (http://creativecommons.org/licenses/by/4.0/). 